\title{
Pengaruh Populasi Mikroba pada Re-fermentasi terhadap Kualitas Biji Kakao Tanpa Fermentasi
}

\section{The Effect of Microbial Population at Re-fermentation on The Quality of Unfermented Cocoa Beans}

\author{
Mulono Apriyanto ${ }^{1, *}$, Yoyon Riono ${ }^{2}$, Rujiah $^{3}$ \\ ${ }^{1}$ Program Studi Teknologi Pangan, Fakultas Pertanian, Universitas Islam Indragiri, Jl. Propinsi parit \\ 1 Tembilahan Hulu, Indragiri Hilir, Riau 29212, Indonesia \\ ${ }^{2}$ Program Studi Agroteknologi, Fakultas Pertanian, Universitas Islam Indragiri, Jl. Propinsi parit 1 \\ Tembilahan Hulu, Indragiri Hilir, Riau 29212, Indonesia \\ ${ }^{3}$ Dinas Tanaman Pangan Hortikultura dan Peternakan, Kabupaten Indragiri Hilir, Riau 29211, \\ Indonesia
}

*Penulis korespondensi: Mulono Apriyanto, e-mail: mulonoapriyanto71@ unisi.ac.id

Tanggal submisi: 27 Juni 2020; Tanggal penerimaan: 08 September 2020

\begin{abstract}
This study aimed to determine the effect of microbial populations on the quality of the cocoa beans produced. This research used unfermented cocoa beans and was then referenced by adding inoculum. Three fermentation techniques were applied in this research. First, control (AO), without the addition of inoculum. Second, S. cerevisiae inoculum (FNCC 3056), L. lactis (FNC 0086), and A. aceti (FNCC 0016), each around $108 \mathrm{cfu} / \mathrm{g}$ is given simultaneously at the beginning of fermentation (A1). Third, the gradual administration of S. cerevisiae inoculum (FNCC 3056) at the beginning of fermentation, L. lactis (FNC 0086) at 24 hours, and A. aceti (FNCC 0016) at 48 hours with the same microbial population as the second treatment (A3). Fermentation was carried out for five days. The results showed that after being rehydrated as much as 50\% weight of the produced dried material, the cocoa beans' composition could be used as a fermentation substrate. The highest population of S. cerevisiae, L. lactis, and A. aceti from three treatments was observed at 24, 48, and 72 hours of fermentation.
\end{abstract}

Keywords: cocoa beans quality, inoculum, re-fermentation, unfermented

\begin{abstract}
ABSTRAK
Tujuan penelitian ini adalah untuk mengetahui pengaruh populasi mikroba terhadap kualitas biji kakao yang dihasilkan. Penelitian ini menggunakan biji kakao yang tidak difermentasi dan kemudian direferensikan dengan penambahan inokulum. Tahapan penelitian yang dilakukan adalah sebagai berikut fermentasi biji kakao dengan 3 variasi teknik fermentasi yaitu perlakuan pertama (A0) tanpa penambahan inokulum (kontrol), kedua (A1) menggunakan inokulum S. cerevisiae (FNCC 3056), L. lactis (FNC 0086) dan A. aceti (FNCC 0016), masing-masing sekitar $10^{8} \mathrm{cfu} / \mathrm{g}$ diberikan secara bersamaan pada awal fermentasi, ketiga (A2) pemberian bertahap inokulum S. cerevisiae (FNCC 3056) pada awal fermentasi, L. lactis (FNC 0086) pada 24 jam dan A. aceti (FNCC 0016) pada 48 jam dengan populasi mikroba sama dengan perlakuan kedua. Fermentasi dilakukan selama 5 hari. Hasil penelitian menunjukkan bahwa setelah direhidrasi sebanyak 50\% dari berat bahan yang dihasilkan komposisi biji kakao dapat digunakan sebagai substrat fermentasi. Populasi S. cerevisiae, L. lactis dan A. aceti tertinggi dari tiga perlakuan pada 24, 48 dan 72 jam fermentasi.
\end{abstract}

Kata kunci: inokulum, kualitas, re-fermentasi, tanpa fermentasi 


\section{PENDAHULUAN}

Secara umum, petani kakao hanya merendam biji kakao segar dalam air dalam upaya membantu menghilangkan pulp dan mengeringkannya di matahari (Apriyanto et al., 2016). Biji kakao yang tidak difermentasi adalah biji kakao segar atau bubur pulp yang baru dibersihkan dan segera dikeringkan. Biji kakao tanpa fermentasi dengan kadar air yang tidak diketahui, dijual tanpa memperhatikan kualitas, baik dari segi kadar air maupun kondisi biji kering disebut sebagai biji kakao acak (Apriyanto dan Umanailo, 2019), (Apriyanto, 2017) dan (Septianti et al., 2020). Sedangkan biji kakao tanpa proses fermentasi diproduksi dengan biji pahit dan tidak ada aroma khas kakao (Hinneh et al., 2019). Fermentasi biji kakao terdiri dari 2 tahap, tahap pertama dimulai dengan menghilangkan pulp dari permukaan biji dan tahap kedua adalah reaksi hidrolitik dalam kotiledon biji (Apriyanto dan Rujiah, 2018).

Fermentasi ulang biji kakao tanpa fermentasi menghadapi beberapa masalah seperti: 1) kadar air pulp yang rendah yang dapat menyebabkan tumpukan biji kakao bersifat aerobik sehingga mengurangi aktivitas ragi yang biasanya aktif dalam kondisi anaerob dan rentan terhadap kontaminasi jamur; dan 2) kehadiran substrat seperti komposisi pulp sangat mempengaruhi populasi mikroba (Júniora et al., 2020; Hernani et al., 2019). Penelitian ini melakukan studi tentang teknik menambahkan inokulum mikroba ke model fermentasi biji kakao yang difermentasi dan mengevaluasi pengaruhnya terhadap perubahan parameter kualitas biji kakao tanpa fermentasi. Dalam penelitian ini telah menjadi pembeda dengan penelitian sebelumnya yaitu optimalisasi pencapaian kadar air pulp minimum biji kakao tanpa fermentasi sebagai syarat untuk proses fermentasi.

\section{METODE PENELITIAN}

\section{Bahan}

Buah kakao curah diperoleh dari Desa Sibuak Jaya, Kecamatan Tapung, Kabupaten Kampar, Provinsi Riau, dengan karakteristik buah matang seperti panjang buah $\pm 15 \mathrm{~cm}$, diameter $\pm 8 \mathrm{~cm}$, kulit buah matang optimal oranye, jumlah biji per polong \pm 35 buah biji.

S. cerevisiae (FNCC 3056), L. lactis (FNCC 0086) dan inokulum A. aceti (FNCC 0016) diperoleh dari laboratorium mikrobiologi Pusat Kajian Pangan dan Gizi di Universitas Gadjah Mada.

\section{Prosedur Penelitian}

\section{Identifikasi Biji Kakao Segar dan Biji Kakao Unfermented}

Biji kakao segar dan biji kakao unfermented diidentifikasi kadar air pulp dan komponen lainnya. Biji kakao unfermented selanjutnya di rendam dalam air dengan perbandingan volume air terhadap berat biji kakao sebesar 60:100 (v/b) untuk mengembalikan kondisi pulp biji kakao segar. Selanjutnya dilakukan perendaman biji kakao untuk mendapatkan kadar air pulp mendekati kadar air biji kakao segar.

\section{Fermentasi Biji Kakao}

Biji kakao hasil identifikasi kemudian difermentasi menggunakan tiga cara. Kotak fermentasi yang digunakan berbasis styrofoam berukuran $75 \mathrm{~cm} \times 40 \mathrm{~cm} \times 32 \mathrm{~cm}$ dengan kapasitas sekitar $40 \mathrm{~kg}$ biji kakao basah. Cara fertmentasi pertama adalah secara spontan (tanpa inokulum) sebagai perlakuan kontrol (A0). Cara fermentasi kedua adalah fermentasi terkontrol dengan penambahan inokulum mikroba (A1). Inokulum mikrobia yang ditambahkan $S$. cerevisiae (FNCC 3056), L. lactis (FNCC 0086) dan inokulum A. aceti (FNCC 0016) secara bersamaan pada awal fermentasi dengan populasi $108 \mathrm{cfu} / \mathrm{g}$ setiap mikrobia. Cara fermentasi ketiga (A2) adalah penambahan inokulum dengan cara sebagai berikut: S. cerevisiae (FNCC 3056) pada awal 24 jam pertama, L. lactis (FNCC 0086) pada awal 24 jam kedua dan A. aceti (FNCC 0016) pada awal 24 jam ketiga, masing-masing dengan populasi $108 \mathrm{cfu} / \mathrm{g}$. Seluruh cara fermentasi menggunakan biji kakao sebanyak $40 \mathrm{~kg}$. Lama waktu fermentasi adalah 120 jam. Tahap ketiga penelitian adalah analisa sampel biji kakao selama fermentasi.

\section{Analisis Biji Kakao}

Analisa yang dilakukan mengacu pada Apriyanto et al. (2016) meliputi analisa kadar air (metode gravimetri) yaitu mengukur selisih berat awal bahan sebelum dan setelah dikeringkan pada suhu $105^{\circ} \mathrm{C}$ selama tertentu hingga penurunan berat konstan. Kadar gula (metode Nelson-Somogy) yaitu diawali dengan membuat kurva standart yaitu diimbang $10 \mathrm{mg}$ glukosa anhidrat (Merck, Germany) dan dilarutkan dalam $100 \mathrm{~mL}$ akuades, 
kemudian buat larutan gula encer dengan kadar gula 0, 2, 4, 6, 8 dan $10 \mathrm{mg} / 100 \mathrm{~mL}$. Selanjutnya masingmasing larutan standar dimasukan kedalam tabung reaksi dan ditambahkan $1 \mathrm{~mL}$ reagensia Nelson. Kurva standar tersebut digunakan untuk menghitung kadar gula reduksi sampel. Larutan sampel diencerkan sampai volume didapat $250 \mathrm{~mL}$ dan disaring dengan kain saring. Diambil $25 \mathrm{~mL}$ larutan sampel dan dimasukkan dalam labu takar $100 \mathrm{ml}$. Bila larutan sampel keruh, ditambah Pb asetat (Merck, Germany) dalam larutan sampel sampai larutan sampel menjadi jernih dan selanjutnya ditambah Na-oksalat seperti penambahan $\mathrm{Pb}$ asetat. Kemudian sampel ditambah $7 \mathrm{~mL}$ akuades dan digojog sampai homogen, selanjutnya OD ditera untuk masing-masing larutan sampel, pada panjang gelombang $540 \mathrm{~nm}$. Dengan prosedur yang sama dilakukan pengukuran OD larutan standar dan dibuat kurva standar untuk dasar penghitungan kadar gula sampel. membuat kurva standart yang menyatakan hubungan antara konsentrasi larutan standart dan OD-nya.

Populasi mikrobia (metode pour plate) yaitu $1 \mathrm{~g}$ sampel pulp biji kakao kering jemur ditambahkan $9 \mathrm{~mL}$ larutan $\mathrm{NaCl}$ 0,85\% (Merck, Germany) selanjutmya dihomogenkan dengan stomaker selama 15 menit. Disiapkan blue tip $1 \mathrm{~mL}$, 7 petridis, 7 tabug reaksi yang masing-maing berisi $9 \mathrm{~mL}$ larutan $\mathrm{NaCl} 0,85 \%$, untuk media pertumbuhan Saccharomyces cerevisiae dibuat dari 7,5 g Peptone (Oxoid, UK), 20 g Glucose (Oxoid, UK), 4,5 g Yeast extract (Oxoid, UK) dan $10 \mathrm{~g}$ agar dilarutakan dalam $1 \mathrm{~L}$ akuades, dan disterilisasi dengan autoclave pada suhu $121^{\circ} \mathrm{C}$ selama 15 menit, untuk media Lactobacillus lactis dibuat dari $52 \mathrm{~g}$ MRS broth (Oxoid, UK), $10 \mathrm{~g} \mathrm{CaCO}_{3}$ (Merck, Germany), $10 \mathrm{~g}$ agar dilarutkan dalam $1 \mathrm{~L}$ akuades, dan disterilisasi dengan autoclave pada suhu $121^{\circ} \mathrm{C}$ selama 15 menit dan untuk media Acetobacter aceti dibuat dari 7,5 g Peptone (Oxoid, UK), $20 \mathrm{~g}$ Glucose (Oxoid, UK), 4,5 g Yeast extract (Oxoid, UK), 50 $\mathrm{mL}$ etanol (Merck, Germany) 90\%, $10 \mathrm{~g}$ agar dilarutkan dalam $1 \mathrm{~L}$ akuades, dan disterilisasi dengan autoclave pada suhu $121^{\circ} \mathrm{C}$ selama 15 menit. Diambil $1 \mathrm{~mL}$ cairan sampel dengan pipet ukur $1 \mathrm{~mL}$ kemudian dimasukan dalam larutan pengencer pada tabung reaksi ke-1 selanjutnya, digojog dengan vortex agar homogen, setelah homogen diambil $1 \mathrm{~mL}$ dan larutan tabung reaksi 1 dimasukan kedalam tabung reaksi ke-2 selanjutnya digojog dengan vortex. Langkah ini dilakukan sampai pada tabung reaksi ke-7. Pengenceran yang telah dilakukan sebanyak 107, kemudian diambil 1 $\mathrm{mL}$ larutan dari tabung reaksi dimasukkan ke-3 sampai tabung reaksi ke-7 kedalam cawan petri kemudian dituang media agar yang sudah dingin sebanyak $\pm 10-15 \mathrm{~mL}$ setiap cawan petri dan di goncang perlahan agar suspensi dalam tabung reaksi tercampur merata.

Selanjutnya cawan petri yang berisi sampel diinkubasi pada suhu $\pm 35{ }^{\circ} \mathrm{C}$ selama 3 hari kemudian, Jumlah koloni mikrobia yang terbentuk dihitung. Penghitungan jumlah koloni menggunakan quebec colony counter (QCC) (Reichert). Diusahakan pertumbuhan sel pada media berkisar antara 30 sampai 300 koloni per cawan petri. Pengukuran populasi mikrobia selama fermentasi dilakukan pada $0,12,24,36,48,60,72$, 84, 96, 108, 120 jam. Populasi mikroba diukur melalui cairan fermentasi dengan cara pengambilan mengacu penelitian (Sebayang, 2006).

Warna biji (metode cut test) yaitu diambil sampel biji kakao kering jemur hasil fermentasi sebanyak 50 butir (pengambilan secara acak). Biji kakao dipotong membujur dengan pisau cutter dan biji terbelah diamati satu persatu untuk mengetahui kondisi biji kakao sebagai biji coklat, biji ungu kecoklatan dan biji slaty. Pengukuran warna biji kakao dilakukan pada akhir fermentasi. Pengukuran suhu dan $\mathrm{pH}$ menggunakan $\mathrm{pH}$ meter dilakukan setiap hari sampai proses fermentasi selesai. Biji kakao dalam penelitian ini menggunakan fermentasi dari biji kakao klon lokal.

\section{Analisis Data}

Penelitian menggunakan rancangan percobaan acak lengkap, pengukuran dilakukan dengan 3 ulangan. Data yang didapat uji statistik menggunakan analisis keragaman satu arah pada tingkat signifikasi 95\%, jika perlakuan berpengaruh nyata maka pengujian dilanjutkan dengan uji lanjut LSD (least significant different) menggunakan program SPSS 17.

\section{HASIL DAN PEMBAHASAN}

\section{Rehidrasi Biji Kakao Tanpa Fermentasi}

Hasil penelitian ini menunjukkan bahwa komposisi pulp biji kakao segar, biji kakao unfermented sebelum dan sesudah rehidrasi disajikan pada Tabel 1. 
Tabel 1. Komposisi pulp biji kakao segar, biji kakao sebelum dan sesudah rehidrasi

\begin{tabular}{lccc}
\hline \multicolumn{1}{c}{ Komposisi } & $\begin{array}{c}\text { Pulp biji } \\
\text { kakao segar }\end{array}$ & $\begin{array}{c}\text { Pulp biji kakao unfermented } \\
\text { sebelum rehidrasi }\end{array}$ & $\begin{array}{c}\text { Pulp biji kakao unfermented } \\
\text { setelah rehidrasi }\end{array}$ \\
\hline Air $(\%, \mathrm{bb})$ & $80,5 \pm 0,3$ & $15,2 \pm 0,5$ & $78,5 \pm 0,3$ \\
Gula total $(\%, \mathrm{bk})$ & $10,2 \pm 0,5$ & $9,3 \pm 0,4$ & $7,5 \pm 0,5$ \\
Gula reduksi $(\%, \mathrm{bk})$ & $5,5 \pm 0,1$ & $4,2 \pm 0,5$ & $3,8 \pm 0,1$ \\
Asam sitrat $(\%, \mathrm{bk})$ & $2,1 \pm 0,2$ & $1,2 \pm 0,3$ & $0,95 \pm 0,5$ \\
$\mathrm{pH}$ & $4,7 \pm 0,1$ & $4,5 \pm 0,2$ & $4,3 \pm 0,2$ \\
\hline
\end{tabular}

Tabel 2. Populasi S. cerevisiae, L. lactis dan A. aceti pada pulp biji kakao segar dan pulp biji kakao

\begin{tabular}{lcc}
\hline \multicolumn{1}{c}{ Mikrobia } & $\begin{array}{c}\text { Pulp biji kakao segar } \\
(c f u / g)\end{array}$ & $\begin{array}{c}\text { Pulp biji kakao setelah rehidrasi } \\
(c f u / g)\end{array}$ \\
\hline S. cerevisiae & $4,5 \times 10^{6} \pm 0,3$ & $3,5 \times 10^{5} \pm 0,3$ \\
L. lactis & $4,2 \times 10^{7} \pm 0,3$ & $4,7 \times 10^{6} \pm 0,3$ \\
A. aceti & $4,6 \times 10^{5} \pm 0,3$ & $4,2 \times 10^{4} \pm 0,3$ \\
\hline
\end{tabular}

Pengukuran komposisi pulp biji kakao dilakukan untuk didapatkan beberapa informasi awal tentang komposisi pulp biji kakao antara lain kadar air, gula total, gula reduksi, asam sitrat dan pH sehingga fermentasi dapat berlangsung. Seperti pada fermentasi biji kakao secara spontan komposisi pulp merupakan subtrat dalam fermentasi biji kakao (Apriyanto et al., 2016). Hasil penelitian ini menunjukkan bahwa komposisi pulp biji kakao sebelum perendaman telah terjadi penurunan gula total, gula reduksi dan penurunan kadar air. Penurunan gula total dan gula reduksi karena telah terjadi perombakan gula oleh mikrobia selama pengeringan, tetapi asam organik yang terbentuk menguap selama pengeringan sehingga pH pulp biji kakao terjadi kenaikan. Penurunan kadar air diduga disebabkan oleh penguapan air karena panas. Perendaman biji kakao dengan aquades pada perbandingan air:berat biji kakao (60:100). Setelah perendaman pulp biji kakao memiiki komposisi berturut-turut sebagai berikut kadar air $\pm 78,5 \%$, kadar gula total $\pm 7,5 \%$ dan gula reduksi $\pm 3,8 \%$. Kadar air pulp biji kakao tidak memenuhi agar terjadinya proses enzimatis pada fermentasi biji kakao, sehingga untuk terjadinya sebuah fermentasi dilakukan pengembalian kadar air pulp biji kakao minimal kadar air pulp menjadi $35 \%$. Pulp merupakan media untuk fermentasi biji kakao, karena pulp memiliki kandungan gula, keasaman serta air yang dibutuhkan untuk pertumbuhan dan perkembangan mikrobia selama fermentasi (Apriyanto et al., 2017).

Hasil penelitian menunjukkan selama pengeringan biji kakao terjadi penurunan komposisi pulp biji kakao dan untuk dapat berlansungnya proses fermentasi pulp biji kakao harus memenuhi syarat sebagai subtrat. Gula total dan gula reduksi pulp biji kakako kering masih memenuhi untuk digunakan sebagai subtrat fermentasi. Proses pengeringan menguapkan air dalam pulp serta seluruh alkohol hasil perombakan gula oleh $S$. cerevisiae berakibat pada tidak berkembang populasi A. aceti. Populasi S. cerevisiae, L. lactis dan $A$. aceti sebesar berturut-turut $3,5 \times 10^{5} \mathrm{cfu} / \mathrm{g}$, $4,7 \times 10^{6} \mathrm{cfu} / \mathrm{g}$ dan $4,2 \times 10^{4} \mathrm{cfu} / \mathrm{g}(\mathrm{cfu}=$ Colony Forming Unit) (Afoakwa et al., 2013). Populasi $S$. cerevisiae, L. lactis dan A. aceti yang terdapat pada pulp biji kakao segar dan pulp biji kakao tersaji pada Tabel 2.

Hasil penelitian ini menunjukkan bahwa setelah perendaman terjadi kenaikan kadar air dapat diduga disebabkan oleh jumlah air yang digunakan cukup membasahi pulp biji kakao jemur. Kadar gula total mengalami penurunan dari 9,3\% menjadi 7,5\% patut diduga telah terjadi proses larutnya sebagian gula total. Jika ditinjau dari kadar air, kadar gula total dan kadar gula reduksi pulp biji kakao yang telah mengalami perendaman dapat layak untuk diferementasi. Penurunan populasi S. cerevisiae karena air dalam pulp biji kakao menguap sehingga pertumbuhan $S$. cerevisiae terganggu dan menyebabkan kematian sel. L. lactis mengalami penurunan diduga karena suhu pengeringan menurunkan kadar air bebas sehingga bakteri tidak dapat tumbuh optimal. Pertumbuhan bakteri membutuhkan air bebas yang lebih banyak dibandingkan yeast. Pada proses pengeringan $a_{w}$ turun, artinya air bebas yang tersisa tidak mencukupi untuk kebutuhan pertumbuhannya, 
walaupun pulp menyediakan nutrisi yang diperlukan (Saunshi et al., 2020).

Air pada pulp sebagai media untuk substrat pada pulp dan massa biji kakao, sehingga proses hidrolisis dan oksidasi senyawa prekursor cita-rasa, dapat berlangsung dengan baik. Selain komposisi pulp biji kakao penelitian ini diperoleh hasil bahwa mikrobia endogenus juga dijumpai pada pulp biji kakao (Agus et al., 2018). Hasil penelitian tahap ini menunjukkan bahwa pada biji kakao telah memiliki populasi S. cerevisiae, L. lactis dan A. aceti, meskipun populasi tersebut belum memadai untuk berlangsungnya fermentasi biji kakao terutama pada awal fermentasi (Lada dan Darmadji, 2014).

\section{Populasi mikroba selama fermentasi dan Warna keping biji (Cut Test)}

Hasil penelitian ini menunjukkan bahwa pada perlakuan kontrol (A0) populasi $S$. cerevisiae, $L$. lactis dan $A$. aceti di awal fermentasi berturut-turut 5,55, 6,66 dan 4,65 log (cfu/g). Pada 24 jam fermentasi terjadi perubahan populasi $S$. cerevisiae, L. lactis dan $A$. aceti berturut-turut yaitu 7,24; 6,70 dan 6,71 log (cfu/g). Pada 48 jam fermentasi populasi $S$. cerevisiae, L. lactis dan A. aceti masingmasing yaitu 5,88, 8,66 dan 6,64 log (cfu/g). Pada 72 jam fermentasi populasi $S$. cerevisiae, L. lactis dan $A$. aceti berturut-turut yaitu 4,23, 8,43 dan 6,11 $\log (\mathrm{cfu} / \mathrm{g})$. Hasil analisis keragaman satu arah menunjukkan bahwa rata-rata populasi $S$. cerevisiae perlakuan A0, A1 dan A2 berturut-turut yaitu 4,93, 5,86 dan 5,66 log (cfu/g) dan tidak berbeda nyata. Hal ini dapat diduga bahwa pengendalian suhu lingkungan menjadi ideal untuk pertumbuhan $S$. cerevisiae. Rata-rata populasi L. lactis menunjukkan bahwa perlakuan kontrol, penambahan inokulum secara serentak dan secara bertahap berturut-turut yaitu 6,90, 8,60 dan 8,55 log (cfu/g) dan perlakuan kontrol menunjukkan berbeda nyata terhadap perlakuan yang lain. Rata-rata populasi $A$. aceti menunjukkan bahwa perlakuan kontrol, penambahan inokulum secara serentak dan secara bertahap yaitu 5,57, 7,78 dan 8,74 log (cfu/g). Hasil uji beda menunjukkan bahwa perlakuan kontrol berbeda nyata $(p \leq 0,05)$ terhadap perlakuan penambahan inokulum secara serentak dan secara bertahap. Perubahan populasi $S$. cerevisiae, L. lactis dan A. aceti yang hasilkan perlakuan kontrol sesuai dengan hasil penelitian (Afoakwa et al., 2013) dan (Afoakwa et al., 2016), yang telah mempelajari pertumbuhan yeast, bakteri asam laktat dan bakteri asam asetat selama fermentasi biji kakao segar sesuai dengan hasil penelitian (Luh et al., 2018) yang telah mempelajari ekologi mikrobia pada fermentasi biji kakao di Indonesia.

Hasil penelitian ini pada perlakuan (A1) diawal fermentasi menunjukkan bahwa populasi $S$. cerevisiae, L. lactis, dan A. aceti diawal fermentasi berturut-turut yaitu 8,28, 8,58 dan 8,57 log (cfu/g). Pada 24 jam fermentasi populasi $S$. cerevisiae, $L$. lactis, A. aceti masing-masing yaitu 12,41, 8,39 dan $8,38 \log (\mathrm{cfu} / \mathrm{g})$, terjadi kenaikan populasi $S$. cerevisiae dari awal fermentasi. Pada 48 jam fermentasi populasi $S$. cerevisiae, L. lactis, A. aceti berturut-turut 5,88, 11,82 dan 8,82 log (cfu/g), populasi L. lactis tertinggi terjadi di 48 jam fermentasi. pada 72 jam fermentasi populasi $S$. cerevisiae, L. lactis dan A. aceti berturut-turut yaitu 4,23, 9,11 dan 10,72 log (cfu/g), terjadi populasi $A$. aceti tertinggi disini. Selanjutnya populasi $S$. cerevisiae, L. lactis dan A. aceti menunjukkan penurunan berturut-turut yaitu 2,5, 6,39 dan 5,45 $\log (\mathrm{cfu} / \mathrm{g})$. Pertumbuhan populasi $S$. cerevisiae, $L$. lactis dan $A$. aceti yang dihasilkan sesuai dengan yang diperoleh Kustyawati dan Setyani (2008); yang telah mempelajari penambahan $S$. cerevisiae (FNCC 3056), L. lactis (FNCC 0086) dan A. aceti (FNCC 0016) pada proses fermentasi biji kakao segar varietas lindak.

Hasil penelitian ini menunjukkan bahwa perlakuan (A2) populasi S. cerevisiae, L. lactis, dan A. aceti diawal fermentasi berturut-turut yaitu 8,66 , 6,64 dan 4,67 log (cfu/g). Pada 24 jam fermentasi populasi $S$. cerevisiae, L. lactis, dan A. aceti naik menjadi berturut-turut 12,55, 8,23 dan 5,53 log (cfu/g). Pada 48 jam fermentasi populasi $S$. cerevisiae, L. lactis dan $A$. aceti terjadi perubahan berturut-turut yaitu 6,54, 12,53 dan 8,73 log (cfu/g). Pada 72 jam fermentasi populasi $S$. cerevisiae, $L$. lactis dan $A$. aceti berturut-turut yaitu 3,87, 10,64 dan 12,13 log (cfu/g). Selanjutnya diakhir fermentasi pada jam ke-120 populasi S. cerevisiae, L. lactis, dan $A$. aceti turun menjadi berturut-turut 2,22, 6,23 dan 9,22 log cfu/g.

Setelah 24 jam fermentasi terjadi kenaikan suhu fermentasi dan $\mathrm{pH}$ lingkungan fermentasi berakibat pada kondisi optimum aktivitas enzim Poligatakturonase (PG) dan dihasilkan etanol lebih banyak sehingga kondisi tidak sesuai untuk $S$. cerevisiae dan perannya digantikan oleh L. lactis. Setelah 48 jam fermentasi subtrat gula sudah relatif sedikit, aerasi semakin baik dan kosentrasi etanol yang relatif tinggi, $\mathrm{pH}$ pulp semakin kecil menjadikan kondisi ideal untuk A. aceti (Afoakwa et al., 2014). 
Persentase warna slaty keping biji kakao antara perlakuan A0 dan A2 menunjukkan berbeda nyata. Rata-rata warna slaty keping biji kakao perlakuan A0, A1 dan A2 berturut-turut yaitu 40,15, 22,19 dan $17,78 \%$. Presentase warna slaty keping biji kakao perlakuan A0, A1 dan A2 menunjukkan dari $65 \%$ turun berturut-turut menjadi 20,53, 0 dan $0 \%$ di 120 jam fermentasi. Hubungan antara populasi mikroba dan warna keping biji tersaji pada Gambar 1, 2 dan 3.

Hasil analisis keragaman satu arah menunjukkan bahwa warna ungu kecoklatan keping biji kakao tidak dipengaruhi oleh variasi teknik fermentasi. Warna ungu kecoklatan keping biji kako kering antar perlakuan menunjukkan tidak berbeda nyata. Rata-rata warna ungu kecoklatan keping biji kakao perlakuan kontrol, penambahan inokulum secara serentak dan secara bertahap berturut-turut yaitu 25,49, 20,25 dan 17,70\%. Presentase warna ungu kecoklatan keping biji kakao diawal perlakuan A0, A1 dan A2 berturut-turut yaitu 30,11,30,13 dan $30,09 \%$. Presentase warna ungu kecoklatan perlakuan A0, A1 dan A2 menunjukkan penurunan berturut-turut yaitu 5,03, 4,98 dan 3,02\% di akhir fermentasi.

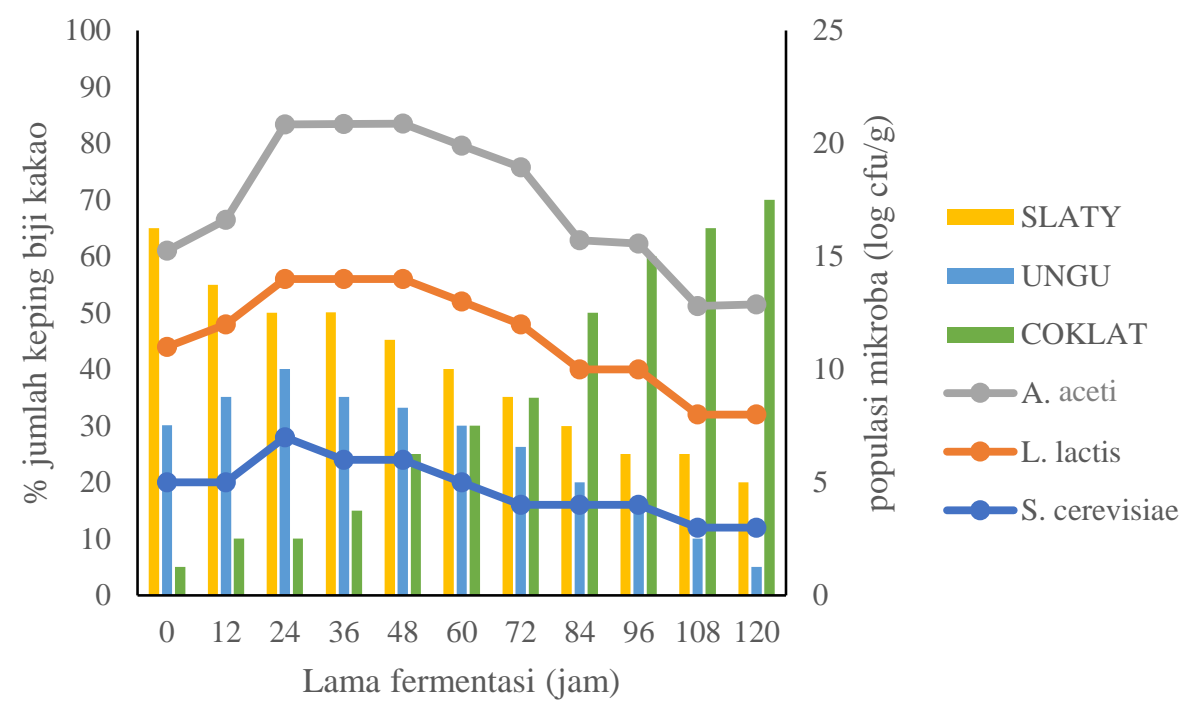

Gambar 1. Hubungan perubahan \% jumlah keping biji kakao berwarna slaty, ungu, coklat terhadap populasi S. cerevisiae, L. lactis dan A. aceti selama fermentasi pada perlakuan A0

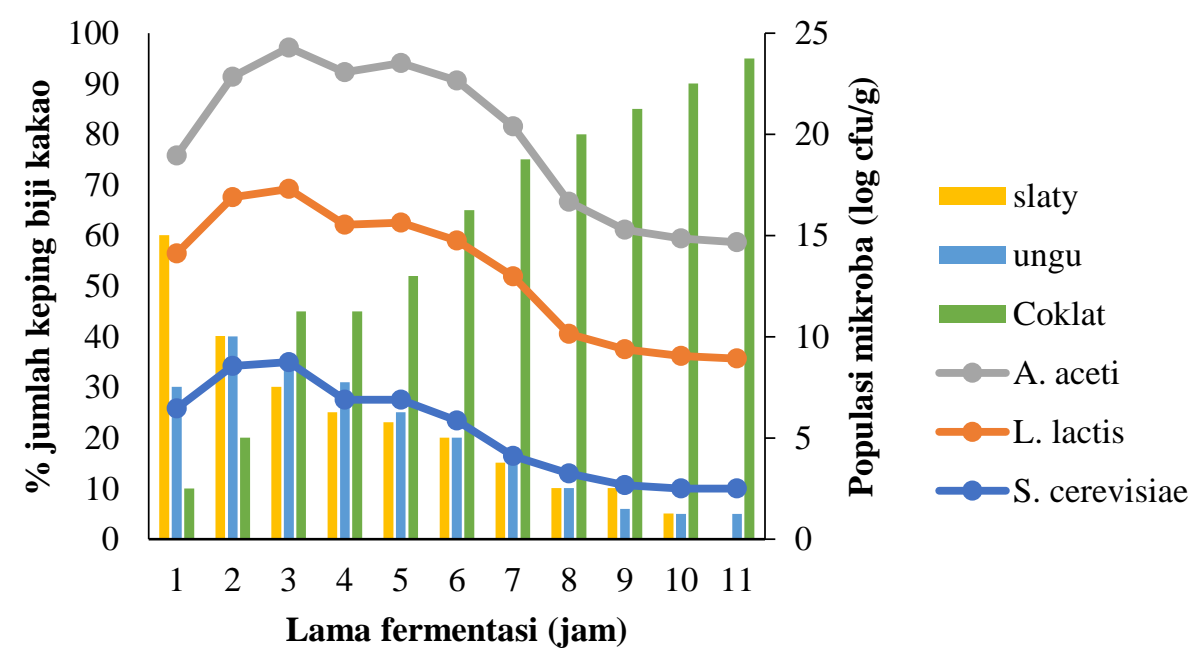

Gambar 2. Hubungan perubahan \% jumlah keping biji kakao berwarna slaty, ungu, coklat terhadap populasi S. cerevisiae, L. lactis dan A. aceti selama fermentasi pada perlakuan A1 


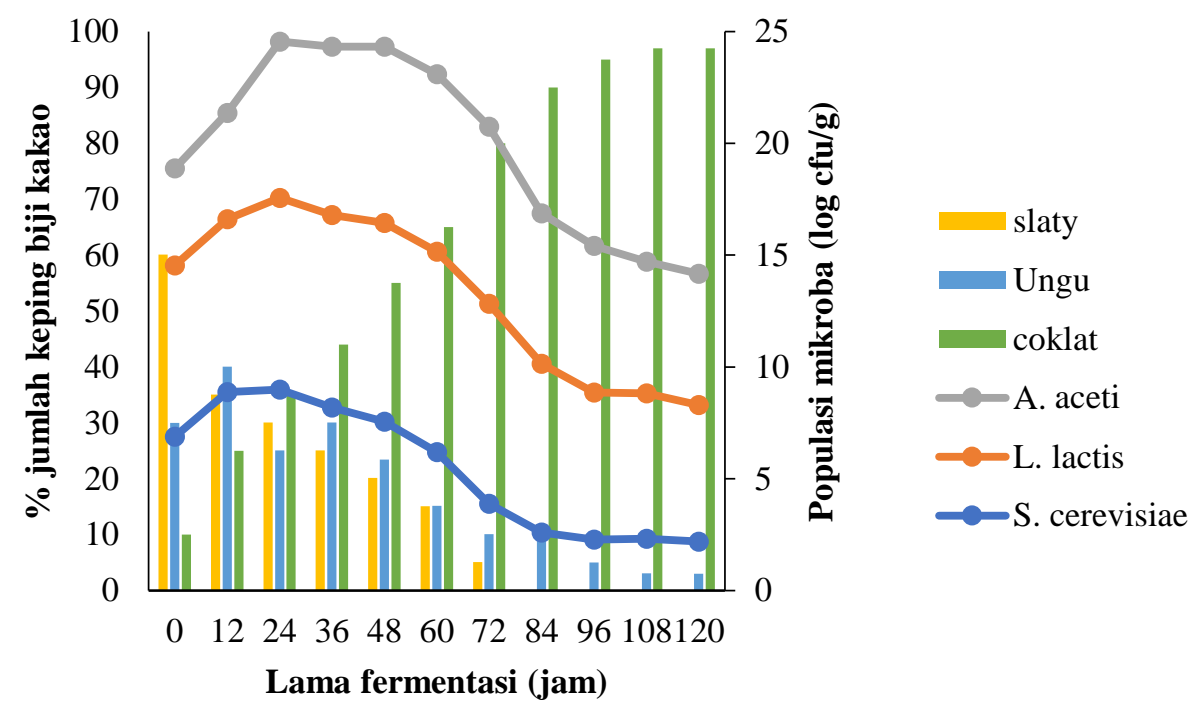

Gambar 2. Hubungan perubahan \% jumlah keping biji kakao berwarna slaty, ungu, coklat terhadap populasi S. cerevisiae, L. lactis dan A. aceti selama fermentasi pada perlakuan A2

Warna coklat keping biji kakao perlakuan kontrol, penambahan inokulum secara serentak dan secara bertahap menunjukkan bahwa tidak berbeda nyata. Rata-rata keping biji berwarna coklat perlakuan kontrol, penambahan inokulum secara serentak dan secara bertahap masing-masing yaitu 34,36, 57,56 dan 64,52\%. Persentase keping biji berwarna coklat perlakuan kontrol, penambahan inokulum secara serentak dan secara bertahap diawal fermentasi berturut-turut yaitu 5,02, 5,02 dan $5,01 \%$ menunjukkan peningkatan diakhir fermentasi berturut-turut yaitu 70,01, 95,03 dan 97,01\%.

\section{KESIMPULAN}

Seluruh pengujian parameter tersebut diatas menunjukkan perlakuan penambahan inokulum secara bertahap mencapai nilai tertinggi dibandingkan kedua perlakuan yang lain. Dari hasil penelitian ini dapat disimpulkan bahwa rehidrasi pulp biji kakao kering dapat memperbaiki komposisi pulp sebagai subtrat fermentasi. Parameter pengujian perubahan populasi mikroba selama fermentasi menjadikan jumlah persentase biji kakao berwarna coklat semakin meningkat.

\section{UCAPAN TERIMA KASIH}

Ucapan terima kasih kepada petani Desa Sibuak Jaya, Kecamatan Tapung, Kabupaten Kampar, Provinsi Riau, menyediakan biji kakao unfermented.

\section{DAFTAR PUSTAKA}

Afoakwa, E.O., A.S. Budu, H. Mensah-Brown, and J. Felix. 2014. Changes in biochemical and physico-chemical qualities during drying of pulp changes in biochemical and physicochemical qualities during drying of pulp preconditioned and fermented cocoa (Theobroma cacao) beans. Journal of Nutritional Health \& Food Science 2: 1-8. DOI: 10.15226/jnhfs.2014.00121

Afoakwa, E.O., J. Quao, J. Takrama, A.S. Budu, and F.K. Saalia. 2013. Chemical composition and physical quality characteristics of Ghanaian cocoa beans as affected by pulp preconditioning and fermentation. Journal of Food Science and Technology 50: 1097-1105. DOI: 10.1007/s13197-011-0446-5

Agus, B.A.P., N.N. Mohamad, and N. Hussain. 2018. Composition of unfermented, unroasted, roasted cocoa beans and cocoa shells from Peninsular Malaysia. Journal of Food Measurement and Characterization 12: 2581-2589. DOI: 10.1007/s11694-0189875-4

Apriyanto, M. 2017. Perubahan pH, keasaman dan indeks fermentasi biji kakao selama fermentasi hasil biji kakao (Theobroma cacao). Jurnal Teknologi Pertanian 6: 12-18. DOI: 10.32520/jtp.v6i1.97

Apriyanto, M. and R. Rujiah. 2018. Penurunan total polifenol, etanol, asam laktat, asam asetat, dan asam amino selama fermentasi biji kakao 
asalan dengan penambahan inokulum. Jurnal Gizi Dan Dietetik Indonesia 5: 1-8. DOI: 10.21927/ijnd.2017.5(1).1-8

Apriyanto, M., Sutardi, E. Harmayani, dan Supriyanto. 2016. Perbaikan proses fermentasi biji kakao non fermentasi dengan penambahan biakan murni Saccharomyces cerevisiae, Lactobacillus lactis, dan Acetobacter aceti. AGRITECH 36: 410-415.

Apriyanto, M., Sutardi, Supriyanto, and E. Harmayani. 2016. Study on effect of fermentation to the quality parameter of cocoa bean in Indonesia. Asian Journal of Dairy \& Food Research 35: 160-163. DOI: 10.18805/ajdfr.v35i2.10724

Apriyanto, M. and M.C.B. Umanailo. 2019. Decrease polyphenols, ethanol, lactic acid, and acetic acid during fermentation with addition of cocoa beans innoculum. International Journal of Scientific \& Technology Research 8: 461-465.

Apriyanto, M., Sutardi, Supriyadi, dan E. Harmayani. 2017. Fermentasi biji kakao kering menggunakan Saccharomyces cerevisiae, Lactobacillus lactis, Acetobacter aceti. AGRITECH 37: 302-311. DOI: 10.22146/agritech.17113

Hernani, T. Hidayat, dan I. Mulyawanti. 2019. The usage of dried starter for re-fermentation of unfermented cocoa beans the usage of dried starter for re-fermentation of unfermented cocoa beans. International Conference on Agriculture Postharvest Handling and Processing 309: 1-7. DOI: 10.1088/17551315/309/1/012061

Hinneh, M., E.E. Abotsi, D. Van de Walle, D.A. Tzompa-Sosa, A. De Winne, J. Simonis, K. Messens, J. Van Durme, E.O. Afoakwa, L. De Cooman, and K. Dewettinck. 2019. Pod storage with roasting: A tool to diversifying the flavor profiles of dark chocolates produced from 'bulk' cocoa beans? (Part I: Aroma profiling of chocolates). Food Research
International 119: 84-98. DOI: 10.1016/j.foodres.2019.01.057

Júniora, P.C.G., A.S.L. Vagner Bezerra dos Santosa, J.P.I. de Souzaa, J.R.S. Pinaa, G.C.A.C. Júniorc, and P.S.B. Marinhoa. 2020. Determination of theobromine and caffeine in fermented and unfermented Amazonian cocoa (Theobroma cacao L.) beans using square wave voltammetry after chromatographic separation. Food Control 108: 106887. DOI: 10.1016/j.foodcont.2019.106887

Kustyawati, M.E., dan S. Setyani. 2008. Pengaruh penambahan inokulum campuran terhadap perubahan kimia dan mikrobiologi selama fermentasi coklat. Jurnal Teknologi Industri dan Hasil Pertanian 13: 73-84.

Lada, Y.G., and P. Darmadji. 2014. Effect of dry bean soaking and roasting instrument material on physical properties, volatile compound profile. AGRITECH 34: 439-447.

Luh, N., P. Novi, A. Aryani, N.L. Yulianti, dan G. Arda. 2018. Karakteristik biji kakao hasil fermentasi kapasitas kecil dengan jenis wadah dan lama fermentasi yang berbeda. Jurnal Beta (Biosistem dan Teknik Pertanian) 6: 1724.

Saunshi, Y.B., M.V.S. Sandhya, N.K. Rastogi, and P.S. Murthy. 2020. Starter consortia for onfarm cocoa fermentation and their quality attributes. Preparative Biochemistry and Biotechnology 50: 272-280. DOI: 10.1080/10826068.2019.1689508

Sebayang, F. 2006. Pembuatan etanol dari molase secara fermentasi menggunakan sel Saccharomyces cerevisiae yang terimobilisasi pada kalsium alginat. Jurnal Teknologi Proses 5: 75-80.

Septianti, E., J. Langkong, N.K. Sukendar, and A.P. Hanifa. 2020. Characteristic quality of pinrang's cocoa beans during fermentation used styrofoam containers. Canrea Journal: Food Technology, Nutritions, and Culinary 3: 10-25. DOI: 10.20956/canrea.v3i1.235 